\title{
Complex scattering within D" observed on the very dense Los Angeles Region Seismic Experiment passive array
}

\author{
M. D. Kohler, J. E. Vidale, and P. M. Davis \\ Department of Earth and Space Sciences, University of California at Los Angeles, Los Angeles, California
}

\begin{abstract}
Several seismic phases that scattered within a few hundred kilometers of the base of the mantle are observed in a very dense seismic section. The Los Angeles Region Seismic Experiment passive phase array was composed of 88 seismometers placed along a $175 \mathrm{~km}$ profile. Records from two deep earthquakes in Tonga and one earthquake near Honshu, Japan show a secondary arrival between clear P and PcP arrivals. Modeling with layered structures shows that the Tonga and Honshu seismic sections are consistent with an increase in seismic velocity 140 and $240 \mathrm{~km}$ above the core-mantle boundary, respectively, and a $\sim 10-\mathrm{km}$ thick low-velocity zone at the base of the mantle beneath a region in the mid Pacific. Several of these arrivals are not coherent enough to appear in higher resolution stacks from the much larger Southern California Seismic Network. This experiment illustrates that finescale passive array data can reveal small-scale deep Earth structure invisible to larger-scale seismic networks.
\end{abstract}

\section{Introduction}

Localized regions in the lowermost mantle are radially and laterally heterogeneous on length scales that vary by orders of magnitude (for review, see Loper and Lay, 1995). Waveform data from permanent networks have been particularly useful to refine small-scale lowermost mantle velocity structure because the number of stations is often large enough to use stacking techniques for structural details (Weber and Davis, 1990; Vidale and Benz, 1992, 1993; Weber, 1993; Mori and Helmberger, 1995; Yamada and Nakanishi, 1996). These studies suggest the presence of thin boundary layers from a few to a few hundred $\mathrm{km}$ above the core-mantle boundary (CMB). Global tomography models exhibit significant lateral velocity variations in the lowermost mantle (Masters et al., 1992; Su et al., 1994), but are limited to resolving only largescale features. Very dense array data provide the highestresolution probe of lowermost mantle structural details, radially and laterally.

The dense Los Angeles Region Seismic Experiment (LARSE) passive array was well-suited for observing deep, fine-scale structural details. Most stations were in seismically quiet locations and were not affected by variations in site conditions. In addition, the majority of teleseismic arrivals from deep events were not distorted by scattered waves due to crustal structure. Short-period teleseismic waveform data show secondary arrivals between $\mathrm{P}$ and PcP not predicted by standard layered Earth models. The phases appear in the data set for the three deepest earthquakes that were recorded.

Copyright 1997 by the American Geophysical Union.

Paper number 97GL01823.

$0094.85 .34 / 97 \cdot 97 \mathrm{GI},-01823 \$ 05.00$
Modeling shows that these arrivals are caused by scattering or layering in the lowermost mantle. Our study demonstrates that fine-scale, temporary seismic array data, originally intended to refine crustal and upper mantle structure, can also resolve features in the deep mantle.

\section{The Dense Los Angeles Region Seismic Experi- ment (LARSE) Passive Array}

The LARSE passive experiment (LARSE93) took place between November 11 and December 16, 1993, and consisted of the deployment of approximately 88 digital, short-period seismometers along a southwest-northeast array in Southern California (Fig. 1) (Kohler et al., 1996). The stations were deployed in a 175-km-long, linear array across the Los Angeles basin, San Gabriel Mountains, and Mojave Desert northeast of Los Angeles. Most seismometers were placed along the part of the line extending from the southern foothills of the San Gabriel Mountains to the northeastern Mojave Desert. The densest part of the array was located in the San Gabriel Mountains with one km average spacing; the Mojave Desert segment had two $\mathrm{km}$ average spacing.

\section{Aligned and Stacked Teleseismic Waveforms}

During the four weeks of continuous recording, the array recorded waveform data from over 100 teleseismic events. Of these, two deep, clearly-recorded events occurred in Tonga

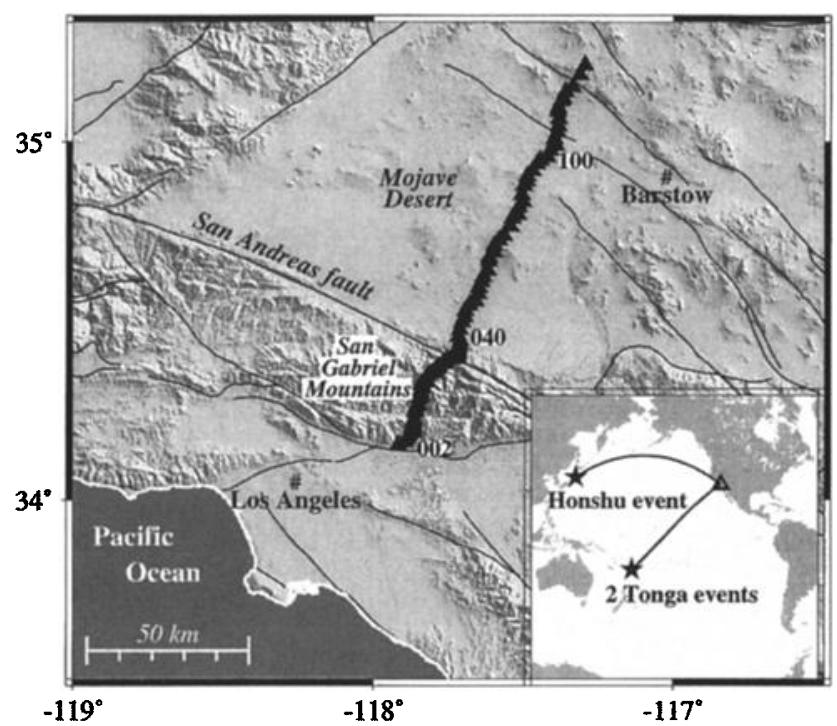

Figure 1. Shaded relief and fault map of Southern California showing locations of LARSE stations (triangles) with several station names for reference. Great circle paths between the earthquakes (stars) and the array (triangle) are shown in inset. 
Table 1. Earthquake source data. Origin information is from the Preliminary Determination of Epicenters.

\begin{tabular}{lccccc}
\hline Location & \multicolumn{2}{c}{ Coordinates } & $\begin{array}{c}\text { GMT Time } \\
\text { date }(\mathrm{hr}: \mathrm{min})\end{array}$ & $\begin{array}{c}\text { Depth } \\
(\mathrm{km})\end{array}$ & $\begin{array}{c}\text { Mag. } \\
(\text { type })\end{array}$ \\
\cline { 2 - 7 } & $\begin{array}{c}\text { latitude } \\
\left({ }^{\circ} \mathrm{N}\right)\end{array}$ & $\begin{array}{c}\text { longitude } \\
\left({ }^{\circ} \mathrm{E}\right)\end{array}$ & & & \\
\hline Tonga 1 & -22.427 & -179.565 & $11 / 19 / 93(04: 37)$ & 591 & $5.3\left(\mathrm{M}_{\mathrm{h}}\right)$ \\
Tonga 2 & -22.180 & -179.575 & $12 / 10 / 93(06: 31)$ & 605 & $5.7\left(\mathrm{M}_{\mathrm{w}}\right)$ \\
Honshu & 38.625 & 141.164 & $11 / 27 / 93(06: 11)$ & 104 & $5.8\left(\mathrm{M}_{\mathrm{w}}\right)$
\end{tabular}

and one occurred in Honshu (Table 1; Fig. 1). The verticalcomponent velocity seismograms for each event were aligned by hand-picking the first prominent $P$ arrival and shifting the traces so that the $P$ wave arrived at the same time for all stations. The seismograms were bandpass filtered for frequencies between 0.1 and $1.0 \mathrm{~Hz}$. Amplitudes were normalized to the peak $P$ amplitude, and polarities were adjusted so that they were the same for each event. Stations with long P coda or with low signal-to-noise ratios were removed from the record sections.

No binning of waveforms was necessary to bring out the phases following the initial $P$ wave. Each aligned record section for the Tonga events displays a secondary arrival between the initial $\mathrm{P}$ wave and PcP for distances around $82^{\circ}$ (Figs. 2a and $2 c)$. It appears 2-3 $s$ after initial $P$ and is not predicted by the Preliminary Reference Earth Model (PREM) (Dziewonski and Anderson, 1981). PcP arrives 4-5 s after initial $P$ with a delayed travel time relative to PREM. Moveout of the secondary phase relative to direct $P$ is uncertain because the distance range of observations is small, so estimates of apparent velocity have large uncertainties. Slant stacks of $P$ waves
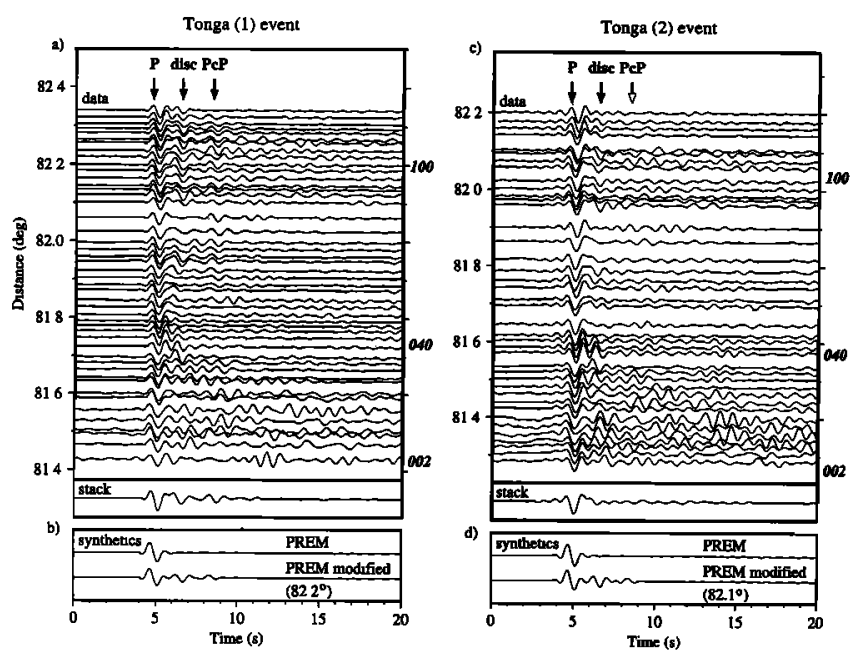

Figure 2. a) Vertical-component velocity record section for earthquake which occurred in Tonga on 11/19/93 showing secondary arrival ("disc"). Station names shown in Fig. 1 are given to the right of the corresponding seismogram; stack of stations from the northern half of the array is shown at bottom. b) Synthetic seismograms produced with PREM and modified PREM (described in text). c) Vertical-component velocity record section for earthquake which occurred in Tonga on 12/10/93; stack is shown at bottom. d) Synthetic seismograms computed as before. from the entire Southern California Seismic Network do not show secondary arrivals other than PcP. Thus, it is unlikely that the arrivals are produced by other earthquake sources otherwise they would have also appeared in the stacks as additional arrivals with zero slowness. No other phases, including crustal reflections, are expected in this time window for these distances and earthquake depths. Empirical source-time functions were removed from the record section of the second larger Tonga event (Fig. 2c) by averaging the traces and deconvolving the result from the waveforms. The same waveform features are seen in a stack produced by binning all recordings from the northern half of the array (Figs. $2 a$ and $2 c$, bottom).

Although such a limited aperture array cannot constrain a unique CMB region structure, we will show below that the data can be explained by a model that is in close agreement to previous results (Mori and Helmberger, 1995; Garnero and Helmberger, 1996). The scattered phases are produced in synthetic velocity seismograms by the generalized rays method for layered structures (Helmberger, 1982) (Figs. 2b and 2d). We assume an empirical source-time function obtained by stacking approximately $2 \mathrm{~s}$ of the direct $\mathrm{P}$ waveform. Modeling results will be discussed below.

The Honshu event record section (Fig. 3) is slightly more complex because the earthquake was not as deep (104 km). The epicentral distance is slightly smaller $\left(77^{\circ}\right)$. A 100 -second time window of the bandpass filtered original data (Fig. 3a) shows the relative amplitudes of $\mathrm{pP}$ and $\mathrm{sP}$, both of which arrive well after $\mathrm{PcP}$ for this distance range. In the aligned section (Fig. 3b), a secondary arrival can be seen 5-6 $s$ after the initial $P$, and a faint $P c P$ arrives 11-12 $s$ after initial $P$. Examination of the horizontal components shows that the arrivals have not been misidentified as converted phases. As before, waveforms with long P coda or with low signal-tonoise ratios have been removed. A stack produced by binning the southern half of the stations (Fig. $3 b$, bottom) shows the same features. The generalized rays synthetics are shown in Fig. 3c.

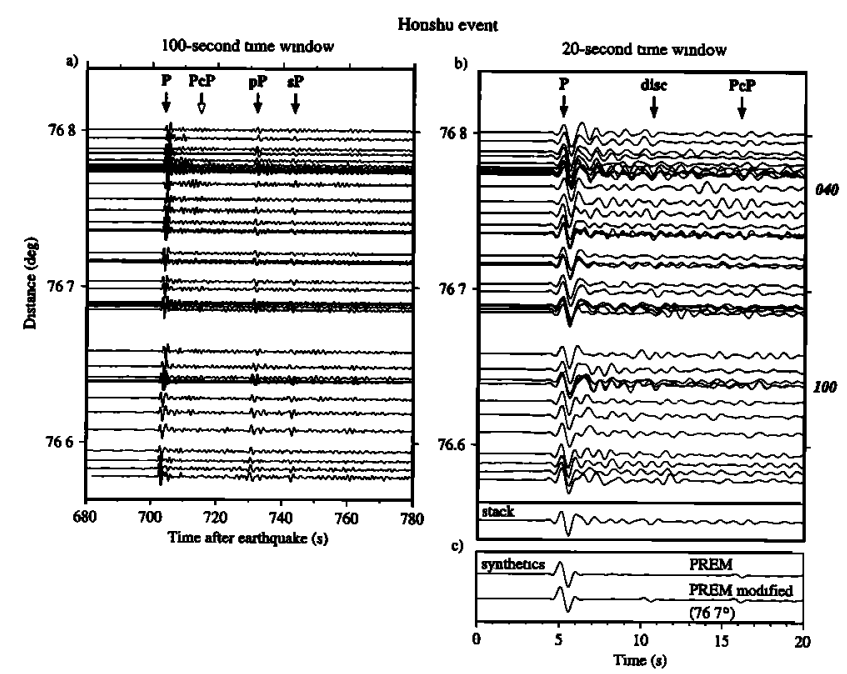

Figure 3. Vertical-component velocity record section for earthquake which occurred near Honshu on 11/27/93 showing secondary arrival ("disc"). b) Aligned seismograms with respect to the first $P$ arrival; stack of southern half of stations is shown at bottom. c) Synthetic seismograms produced with PREM and modified PREM (described in text). 


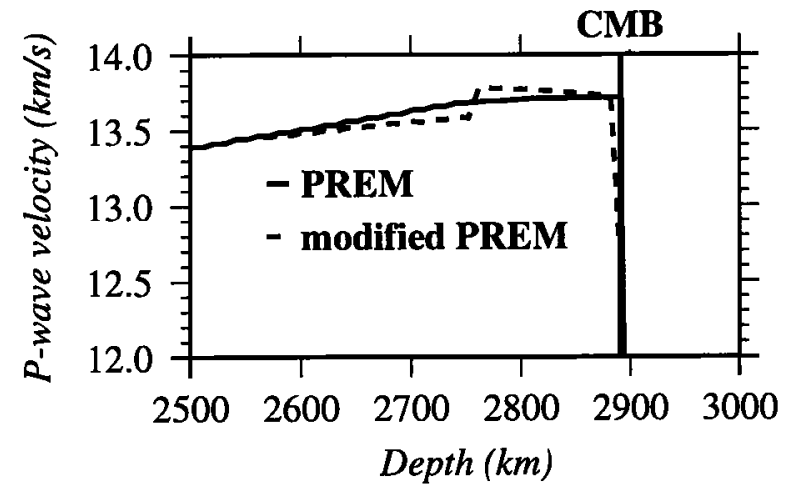

Figure 4. Earth models PREM and modified PREM (described in text) used to produce synthetics for Tonga events. CMB depth is shown by the bold vertical line.

Synthetic modeling using the one-dimensional PREM is unable to explain characteristics of the observed phases (Figs. $2 \mathrm{~b}$ and $2 \mathrm{~d}$ : top). The secondary arrival after $\mathrm{P}$ is not produced and $\mathrm{PcP}$ arrives earlier than observed with an amplitude that is too small. The synthetic seismograms shown at the bottom of Figs. $2 \mathrm{~b}$ and $2 \mathrm{~d}$ demonstrate that relative travel times and amplitudes of the Tonga records are consistent with a $10-\mathrm{km}$ thick low-velocity zone at the base of the mantle and a small, positive velocity perturbation $140 \mathrm{~km}$ above the CMB. The synthetic arrivals were produced by perturbing PREM $P$ and $S$ velocities by $-8 \%$ in the lowermost $10 \mathrm{~km}$ of the mantle, and by $1.5 \%$ at a discontinuity $140 \mathrm{~km}$ above the CMB. The first perturbation was defined by a negative linear gradient for values between $0 \%$ and $-8 \%$ over the lowermost $10 \mathrm{~km}$ (see Fig. 4). The second was defined by a negative linear gradient for values from $0 \%$ to $-0.75 \%$ between $340 \mathrm{~km}$ and $140 \mathrm{~km}$ above the $\mathrm{CMB}$, leading to a $1.5 \%$ step increase in velocity, followed by a second negative, linear gradient for values from $0.75 \%$ to $0 \%$ between $140 \mathrm{~km}$ and $10 \mathrm{~km}$ above the CMB (Fig. 4). The amplitude of the secondary phase produced by this perturbation is large because it is near the caustic. The combination of gradients for the second case was designed so that the lower mantle would not be slower or faster than average over the $340 \mathrm{~km}$ depth range. It should be noted that velocity perturbation ranges of $-6 \%$ to $-10 \%$ for the lowermost $10 \mathrm{~km}$, and $1 \%$ to $2 \%$ for $140 \mathrm{~km}$ above the CMB produced satisfactory fits to the data. When the basal layer thickness was increased to $20 \mathrm{~km}$ or more, the synthetic PcP pulse width was larger than observed. Raising the lower mantle discontinuity height to greater than $160 \mathrm{~km}$ above the CMB caused the secondary arrival to interfere with initial $\mathrm{P}$ because it arrived too early; lowering it to less than $120 \mathrm{~km}$ caused the phase to arrive later than observed. Observations similar to these have been reported for stacked data (Vidale and Benz, 1992; Mori and Helmberger, 1995; Yamada and Nakanishi, 1996) but have not been made from record sections of individual seismograms observed on such closely-spaced stations. The Honshu waveforms were modeled by perturbing PREM velocities by $1 \%$ to $2 \%$ (defined as before) $240 \mathrm{~km}$ above the $\mathrm{CMB}$; the lowermost mantle in this region of the northernmost Pacific was left normal relative to PREM. Although the data set is not large enough to obtain formal errors, the synthetic seismogram modeling suggests that uncertainty of the discontinuity depth is $\sim 20 \mathrm{~km}$, and of the D" low-velocity zone thickness is $5-10 \mathrm{~km}$. We computed sections of syn-

thetic seismograms for the same distance ranges given by the data which confirm that moveout of the reflected phase relative to $P$ is difficult to observe for our limited distance ranges. As Mori and Helmberger (1995), and Garnero and Helmberger (1996) note, the D" low-velocity zone corresponding to the Tonga event reflection region falls within a low-velocity anomaly seen in global velocity models (e.g., Masters et al., 1992; Su et al., 1994) and is interpreted as a thermal or compositional boundary layer. The D" reflection region corresponding to the Honshu event (in the northern Pacific) falls within a region of little or no anomaly.

The secondary arrivals are evident in envelopes of slant stacks of the $P$ wave created from the aligned teleseisms. The slant stack of the LARSE data for the first Tonga event is shown in Fig. 5a where each point in the the slant stack represents the sum along a line through the aligned section described by a slowness and delay time with respect to direct P. The envelope of the slant stack illustrates the logarithmic variations in amplitude given by the slant stack, thus allowing the observation of over two orders of magnitude change in phase amplitude. Direct $\mathbf{P}$ is the first strong arrival (indicated in red), the secondary arrival appears about $2 \mathrm{~s}$ later (indicated in yellow), and PcP appears about $5 \mathrm{~s}$ after direct $\mathrm{P}$ (also in yellow). Slownesses of the scattered phases are $<0 \mathrm{~km} / \mathrm{s}$ and are consistent with the model suggested here. Because the slant stack represents regions of constructive interference, the slownesses and arrival times can fall anywhere within the brighter color shadings indicating the uncertainty in these values. For comparison, the background noise level (approximately 100 times smaller in amplitude) is indicated by purple or black regions.

An envelope slant stack was made of the waveforms recorded by the cleanest 86 Southern California Seismic Network stations for the same Tonga event (Fig. 5b). This stack shows the initial $P$ arrival (red), followed $\sim 4 \mathrm{~s}$ later by PcP energy. The secondary arrival is not coherent enough across the much larger network to appear in the slant stack. The stations are $15-30 \mathrm{~km}$ apart and the lack of coherence is probably due to the larger network aperture. Rays arriving across the network sample a much larger patch of laterally varying low-

\section{Envelope stacks of $P$ wave}

a) LARSE passive array

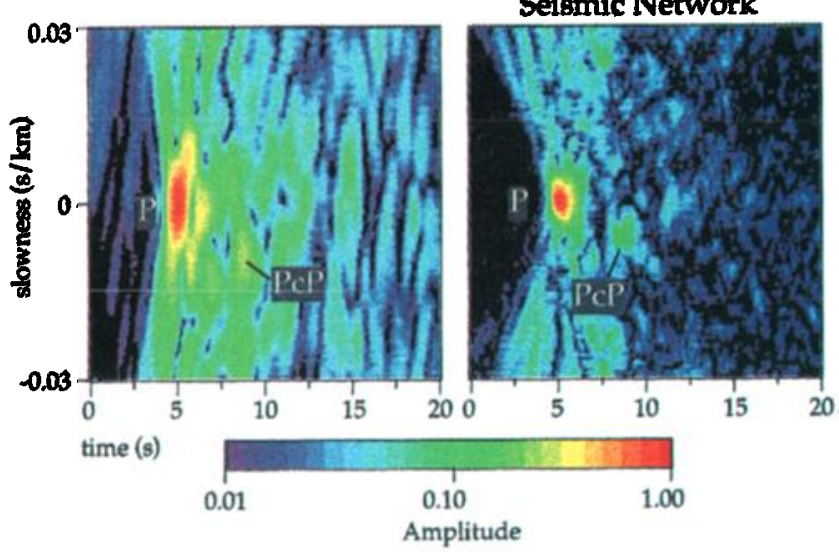

Figure 5. a) Envelope stack for the first Tonga event using the LARSE passive array data. Slowness is shown relative to initial P. b) Envelope stack using 86 Southern California Seismic Network stations for the same event. 
ermost mantle. $\mathrm{P}$ and PcP slowness and travel-time uncertainties are higher for the LARSE array because rays intersect the smaller array broadside. The difference in PcP slowness between the network and the LARSE array is due to the inclusion of the larger number of network stations to the east that have larger source-receiver distances.

\section{Observing Earth Structure on Dense Arrays}

The LARSE passive phase provided a unique data set in which to observe body waves along a finely $(1-2 \mathrm{~km})$ spaced profile in Southern California. The passive array data show scattered mantle and core phases that are not resolved by larger networks. Modeling of record sections including PcP and the secondary arrival produced by events in Tonga shows that they are consistent with a $10-\mathrm{km}$ thick, lowermost mantle layer with a $-6 \%$ to $-10 \% \mathrm{P}$-wave velocity perturbation, and a discontinuity $\sim 140 \mathrm{~km}$ above the CMB with a $1 \%$ to $2 \%$ velocity perturbation. The patch of lowermost mantle sampled by the LARSE passive phase raypaths overlaps a portion of that sampled by the Mori and Helmberger (1995) data set that included PcP waveforms recorded by California stations from deep Fiji events. They concluded that the lowermost mantle is composed of a $10-\mathrm{km}$ thick layer with a velocity reduction of $5 \%$ to $10 \%$, but were unable to resolve a reflector between $\mathrm{P}$ and PcP. Garnero and Helmberger (1996) observed late $S_{\mathrm{d}} \mathrm{KS}$ travel times relative to SKS and proposed the existence of a $40-\mathrm{km}$ thick layer above the CMB with velocity reductions of $10 \%$ for a section of lowermost mantle $1000 \mathrm{~km}$ to the southwest; they have not reported anomalous scattering for the region, however. The relative arrival times and amplitudes of the LARSE Honshu waveforms can be modeled by a normal D" region and a $1 \%$ to $2 \% \mathrm{P}$-wave velocity perturbation $-240 \mathrm{~km}$ above the CMB. This is near a larger region beneath the northernmost Pacific in which a reflector has been proposed to exist between 218 and $268 \mathrm{~km}$ above the CMB from ISC secondary arrival information (Weber and Körnig, 1992).

The high resolution observations show a large degree of coherence for adjacent stations and constrain small-scale complexity in models of heterogeneity for regions of the lowermost mantle. The Southern California Seismic Network, in comparison, has a larger average station spacing and spans a much larger area making it more difficult to observe scattered phases without stacking and binning. Scattered energy from lowermost mantle boundary layers may be filtered out through the binning process due to the larger distance range. Such layering near the $\mathrm{CMB}$ may be produced by strong thermal or compositional contrasts (see Loper and Lay, 1995, for review). The lowermost mantle seismic gradients that we observe can be explained by thermal effects only if the vertical temperature gradients are extremely large, possibly the result of partial melt; alternatively, they may be due to chemical heterogeneity in regions of Si or Fe enrichment (Loper and Lay, 1995).

Permanent and temporary passive arrays can provide high resolution structural details about localized regions of deep
Earth structure. Passive array data from temporary installations in poorly-instrumented areas have the potential of obtaining structural information about regions that are not covered by permanent seismic networks. In addition, dense short-period and broadband seismic arrays can improve resolution of fine-scale features of regions that have already been instrumented with sparse networks.

Acknowledgments. LARSE93 was a joint effort involving scientists from the University of California at Los Angeles, the U.S. Geological Survey, the California Institute of Technology, and the University of Southern California. Our appreciation goes to Ed Garnero for providing the generalized rays synthetic seismogram code. The manuscript was greatly strengthened by comments from Michael Weber and Don Helmberger. This work was funded by the Southern California Earthquake Center (contribution number 353 ) and by National Science Foundation grant EAR 96-28051.

\section{References}

Dziewonski, A. M., and D. L. Anderson, Preliminary reference Earth model, Phys. Earth Plan. Int., 25, 297-356, 1981.

Garnero, E. J., and D. V. Helmberger, Seismic detection of a thin laterally varying boundary layer at the base of the mantle beneath the central-Pacific, Geophys. Res. Lett., 23, 977-980, 1996.

Helmberger, D. V., Theory and application of synthetic seismograms, in Earthquakes: Observation, Theory and Interpretation, edited by $\mathrm{H}$. Kanamori and E. Boschi, pp. 174-222, North-Holland Publishing Company, New York, 1982.

Kohler, M. D., P. M. Davis, H. Liu, M. Benthien, S. Gao, G. S. Fuis, R. W. Clayton, D. Okaya, and J. Mori, Data report for the 1993 Los Angeles Region Seismic Experiment (LARSE93), Southern California: a passive study from Seal Beach northeastward through the Mojave Desert, U.S. Geological Survey Open-File Report, 96-85, 1996.

Loper, D. E., and T. Lay, The core-mantle boundary region, J. Geophys. Res., 100, 6397-6420, 1995.

Masters, G., H. Bolton, and P. Shearer, Large-scale 3-dimensional structure of the mantle (abstract), Eos Trans. AGU, 73, 201, 1992.

Mori, J., and D. V. Helmberger, Localized boundary layer below the mid-Pacific velocity anomaly identified from a PcP precursor, $J$. Geophys. Res., 100, 20359-20365, 1995.

Su, W.-J., R. L. Woodward, and A. M. Dziewonski, Degree 12 model of shear velocity heterogeneity in the mantle, $J$. Geophys. Res., 99, 6945-6980, 1994.

Vidale, J. E., and H. M. Benz, A sharp and flat section of the coremantle boundary, Nature, 359, 627-629, 1992.

Vidale, J. E., and H. M. Benz, Seismological mapping of fine structure near the base of the Earth's mantle, Nature, 361, 529-532, 1993.

Weber, M., P- and S-wave reflections from anomalies in the lowermost mantle, Geophys. J. Int., 115, 183-210, 1993.

Weber, M., and J. P. Davis, Evidence of a laterally variable lower mantle structure from P- and S-waves, Geophys. J. Int., 102, 231$255,1990$.

Weber, M., and M. Körnig, A search for anomalies in the lowermost mantle using seismic bulletins, Phys. Earth and Plan. Int., 73, 1 28, 1992.

Yamada, A., and I. Nakanishi, Detection of P-wave reflector in D" beneath the south-western Pacific using double-array stacking, Geophys. Res. Lett., 23, 1553-1556, 1996.

Department of Earth and Space Sciences, University of California at Los Angeles, Los Angeles, CA 90095-1567

(Received October 28, 1996; Revised March 19, 1997; Accepted May 21, 1997) 